the corolla, $(b)$ its excision, (c) loss of colour, $(d)$ closing, $(e)$ not opening, $(f)$ absence of insects, $(\sigma)$ reduction of temperature, $(h)$ transportation. 5. Highly self-fertile forms may arise under cultivation. 6. Special adaptations occur for self-fertilisation. 7. Inconspicuous flowers are highly self-fertile. 8 . Cleistogamous flowers are always self-fertilised. 9. Conservation of energy in reduction of pollen. 10. Relative fertility may equal or surpass that of crossed plants. II. It does not decrease in successive generations. 12. It may ircrease. 13. Free from competition self-fertilised plants equal the intercrossed; $(a)$ as seedlings, $(b)$ planted in open ground. I4. They may gain no benefit from a cross from the same or a different stock. 15. They are as healthy as the intercrossed. 16. They may be much more productive than fowers dependent upon insects, 17. Naturalised abroad they gain great vigour; and ( 18 ) are the fittest to survive in the struggle for life.

Physiological Action of Nicotin-About twenty years ago the Rev. Prof. Haughton called attention to the fact that there was an antagonism between the actions of nicotin and of strychnia. His experiments were on frogs. About ten years afterwards Dr. Wormley experimented in the same direction with cats; and some five years ago Dr. Reese performed a series of experiments with these drugs on dogss. Not satisfied with the results of any of these experimenters and recognising the great importance of the subject, Dr. Haynes has made a longr series of experiments on doss, cats, rabuits, and rats, and aiter some 143 experiments, has come to the folluning conciusions:- "The recorded cases of strychnia voisonirg treated by tobacco are extremely unsatisfactory. If they prove anything it is merely that tobacco is a pwerful emetic." "Haughton's experimerits on this subject (really only two in number) were performed in such an unscientific manner as to be utterly valueless." "Strychnia and nicotin are in no degree antagonistic poisons." "Strychnia increases the convulsive action and dces not diminish the motor paralysis of nicotin." "Nicotin (even in paralysing doses) increases the cor:vulsive action of strychnia." "Both poisons cause death by paralysing the respiratory organs. They may affect respiration in different ways, but the result is the same." Animals may be killed by injecting together doses of the two drugs which, singly, are not fatal. (Procedings of the American Philosophical Society, vol. xvi., No. 99.)

Glassy Sponges.-Drs. W. Marshall and A. B. Meyer have published a memoir, as one of a series of communications to the Zoological Museum at Dresden, "on some new or little-known sponges belonging to the Hexactinellida found in the Philippines." It seems but the other day since one could have numbered on the fingers of one hand all the known species of this family, so well known to many by that beautiful typical form, the Venus's flower-basket (Euplectella), and now the number of described species is very large. In 1872 one of the authors (Dr. Meyer) was staying at Cebú one of the Philippine group, where Eupiectella aspergillum is a regular article of trade, quoted at so much a dozen, and where it is not surprising that he should discover a number of other lovely forms in this memoir described and figured. Among the more interesting forms are the following:-Hyalocaulos simplex, Myizusia zittelii, and two species of Aulodictyon, all of these found living attached to the basal portion of Euplectella. Semperella schultzei is figured of a natural size from a specimen twenty-one inches in length, and figures of the spicules of the various new species are also given.

A MALE NURSE. - The interest of the reproduction of Batrachians is by no means yet exhausted. A Spanish naturalist, Jimenez de la Espada, has recently discovered additional facts respecting Rhinoderma darwinti (of Chili), which was first made known by Mr. Darwin.
He finds that the supposed viviparous birth of the young from the female is a very different phenomenon. It is the males which are the nurses, and they have an extraordinary brood-sac, developed as a pouch from the throat, and extending over a great portion of the ventral surface of the animal. In this cavity a number of living tadpoles were found, in number of individuals, and the length of the tadpoles was about $14 \mathrm{~mm}$. How these are first developed and nourished is not yet known. Dr. J. W. Spengel translates a portion of the Spanish paper in the current number of the Zeitschrift firr zetissenschaftliche Zoologic, vol, xxix. part 4 .

Structure OF CYCADEA.-E. Warming, of Copenhagen, publishes (in Danish with French abstract) some fresh researches on this subject "Recherches et Remarques sur les Cycadées," Copenhagen, 1877). He confirms in general the results previously arrived at by A. Braun and others, from the structure of the ovule and seed, the pro-embryonic characters, the mode of formation of the pollen and pollen-plant, and of the growth of the stem and roots, \&c., that the Cycadece are very nearly allied to the Conifera; and in particular he places them near to the Girigko (Salisburia alibutifolia). Among Cryptogams he considers them to cone nearest to Marattiacee and Ophioglossacex among Filicinea. He proceeds then to disciss the homology of the ovule of Phanerogans, on which he thinks the structure of that of the Cycads-intermediate between Vascuiar Cryptogams and Angiosperns - throws much light. The phanerogamic ovule ine consicers to be composed of two parts, of different mor tholugical origin, viz., a rucleus Which is bomelogous with the inacrosporangium; and a lobe of the leat which bears the nucleas, consising partiy of the funiculus and partly of the integuments. In Angiosperms the nucleus rests on the surface of the leaf; in Gymnosperms it is parly inbedded in it. No part of the ovule is of axial origin (caulome).

The Brain of a Fossll Mammal.-Prof. Cope has been able to titke a cast of the cranial cavity of a specie of the Tapiroid gerus Caryphodon, from the Vahsatch beds of New Mexico. This has revealed renarkable primitive characters : (I) the small size of the cerebellum; $(z)$ the large size of the region of the corpora quadrigemina; (3) the cerebral henispineres were small, and (4) the olfactory lobes were very large. The niedulla oblongata is wider thail the cerebral hemispheres. In profile the brain closely resemb!'es that of a lizard. These cbaracters are so extraordinary that Prof. Cope considers them sufficient to mark a primary division of mammalia, which he, following Owen, calls Protencephala. Prof. Cope describes and gives figures of a cast, the skull cavily, in the Proceedings of the American Philosophical Society, vol. xvi., No. 99.

\section{INSECTIVOROUS PLANTS}

SINCE the appearance of Mr. Darwin's work on "Insectivorous Plants" the want of direct proof that the plants profit by their carnivorous habits has been somewhat widely felt. Thus we find expressions to this effect by MM. Cassimir de Candolle, Cramer, Duchartre, Duval-Jouve, Faivre, Göppert, E. Morren, Munk, Naudin, W. Pfeffer, Schenk, \&c., \&c.

The assent which many naturalists have given to $\mathrm{Mr}$. Darwin's explanation of the meaning of the structure and physiological properties of carnivorous plants rests on a sound basis, namely, the impozsibility of believing that highly specialised organs are unimportant to their possessor, and the difficulty of giving any rational explanation except the one proposed in "Insectivorous Plants." Mr. Darwin himself felt the desirableness of direct evidence on this head, and the experiments intended to I From a paper "On the Nutrition of Drosera rotundifolia," by Francis Darwit, $M$. 1 , , read before the Linmean Society, January 17,1878 . 
decide the question only failed through an accident. The present research by Dr. F. Darwin is practically a repetition of the same experiments.

The widely-spread belief that insectivorous plants thrive equally well when deprived of animal food rests on very insufficient grounds. Many observers have based their opinion on the general appearance of the plants, and in no case has observation been sufficiently extended in point of time or details of comparison. The plan of the present research was therefore (I) To cultivate a large number of plants. (2) To continue observation for a considerable space of time, during which artificial starving and feeding of two sets of plants was to be kept up.

To compare the starved and fed plants in a variety of ways and especially as to the production of seed.

With this object about $2 \mathrm{co}$ plants of Drosera rotundifolia were transplanted (June 12, 1877), and cultivated in soup-plates filled with moss during the rest of the summer.

Each plate was divided into halves by a low wooden partition, one side being destined to be fed with meat, while the plants in the opposite half were to be starved. The plates were placed altogether under a gauze case, so that the "starved" plants might be prevented from obtaining food by the capture of insects. The method of feeding consisted in supplying each leaf on the fed sides of the six plates) with one or two small bits of roast meat, each weighing about one-fiftieth of a grain. This operation was repeated every few days from the beginning of July to the first days of September, when the final comparison of the two sets of plants was made. But long before this it was quite clear that the "fed" plants were profiting by their meat diet. Thus, on July I 7 it was evident that the leaves on the "fed" side were of a distinctly brighter green, showing that the increased supply of nitrogen had allowed a more active formation of chlorophyll-grains to take place. It may be inferred, partly from microscopical examination of the starch in the leaves, but more certainly from the final comparison of dry weights, that the increase of chlorophyll was accompanied by an increased formation of cellulose. From this time forward the "fed" sides of the plates were clearly distinguishable by their thriving appearance and their numerous tall and stout flower-stems.

The advantage gained by the fed plants was estimated in many ways. Thus, on August 7 the ratio between the number of "starved" and "fed" flower stalks was Ioo: 149'1. And by comparing the number of stems actually in flower it was clear that the starved plants were losing the power of throwing up new flower stems at an earlier date than their rivals. In the middle of August the leaves were counted in three plates, and were found to be 187 on the starved, and 256 on the fed side-or in the ratio of $100: 136.9$.

At the beginning of September the seeds being ripe, all the flower-stems were gathered, and the plants of three plates were picked out of the moss and carefully washed. As it seemed probable that one advantage of the fed over the starved plants would be the power of laying by a larger store of reserve-material, three plates were allowed to remain undisturbed after the flower-stems had been gathered. The relative number of plants which will appear in the spring on the "fed" and "starved" sides will be a means of estimating the relative quantities of reserve-material.

The following list gives the result of counting, measuring, and weighing the various parts of the two sets of plants. It will be seen the number of plants (judging from the three plates examined) were fairly equal on the starved and fed sides of the partitions so that a direct comparison of their produce is allowable :-

Ratio between the number of starved and

$$
\begin{array}{lllllll}
\text { fed plants } & \ldots & \ldots & \ldots & \ldots & 100: 102^{\prime}
\end{array}
$$

$$
\text { In a!l casts "starved" }=100 .
$$

Ratio between weights of the plants $e x$. clusive of flower-stems ...

Total number of flower stems $\ldots . \quad \ldots \quad$ IOO : 164.9

Sum of the heights of the flower stems ... 100 : $159^{\circ} 9^{1}$

$\begin{array}{llll}\text { Total weight of flower stems } & \ldots & \ldots & \text { roo : 23 I }{ }^{\circ}\end{array}$

Total number of capsules... $\quad \ldots \quad \ldots$ IOO : I 94.4

Average number of seeds per capsule ... 100:1227

Average weight per seed ... $\ldots . . . . . \quad 100: 1573$

Total calculated number of seeds produced

\subsection{3}

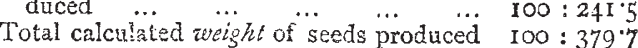

The most important feature in the general result is that the advantage gained by the fed plants is far more conspicuously shown in all that relates to the seeds and flower-stems than in any other part. 'Thus the ratio between the weights of the plants, exclusive of flowerstems were as 100 to I2I'5; while the weights of the flower-stems, including seeds and capsules, were as roo to 23 I'9. The highest ratio is seen to be between the total weights of seed produced, namely $100: 3797$; and this is intelligible, because a store of nitrogen is laid by in the albuminous seeds.

Another point is that the difference between the starved and fed plants is more clearly shown in the comparison of weights than of numbers or heights. It is clear that increase of weight is a better proof of increased assimilation than any other character.

It may fairly be said that the above experiments prove beyond a doubt that insectivorous plants are largely benefited by a supply of animal food, and it can no longer be doubted that a similar benefit is gained in a state of nature by the capture of insects.

\section{ALBERT VON HALZER}

$\mathrm{N}$ December i2 last the republic and city of Berne celebrated the centenary of the death of one who is universally recognised as their greatest citizen. The important part played in science by Albert von Haller last century is a sufficient excuse for us, profiting by the occasion of the recent celebration, to enable our readers to appreciate the marvellous aptitude of this eminent man for every kind of work, theoretical and practical; he was at once a statesman, theologian, and poet, as well as a physiologist, anatomist, and botanist.

Albert Haller was born at Berne in October, 1708, of a family originally of St. Gall, one of whose members fell by the side of Zwingli in I53 I. Very weak in body, like Isaac Newton, in his infancy, he exhibited, like hin, an extraordinary precocity, and his avidity for books was something indescribable. Having finished his classical studies brilliantly and rapidly, he went to Tübingen at the age of fifteen years to study medicine, then soon afier to Leyden to follow the clinic of the illustrious Boerhaave, on whose works he at a later time published a commentary which greatly contributed to his renown. Albinus taught him anatomy and J. Gessner botany. At eighteen and a half years he obtained the degree of doctor, and afterwards attended, in London, the teaching of Dr. Winslow. After a sojourn at Paris he returned to Switzerland and studied mathematics with Jean Bernoulli, and that with such ardour that his friends were constrained to look after him.

In 1728 he made, with Gessner, his first great Alpine excursion, which, many times repeated, made him, in an eminent degree, master of the Swiss flora. His most celebrated poem, entitled "Die Alpen," was another result of his mountain journeys, which contributed to diffuse among those far away the magic charm of that magnificent scenery. ${ }^{2}$

Therefore the average height of the fed stems is slightly less (100:99'9) than that of the fed. But since equal numbers of plants are taken, the total yield of flower stems is the fair criterion.

Prince Radzwil, Commander of the Polish Confederates, having at a later period become acquainted with the poem, could not think ot anything better to signify to the author his satisfaction, than to serd him a commission of Major-General. 